\title{
Harbour oscillation: a numerical treatment for undamped natural modes
}

\author{
C. TAYLOR, B. S. PATIL \& O. C. ZIENKIEWICZ
}

Dr B. W. Wilson, Consulting Oceanographic Engineer, Pasadena, California, USA The Authors have mentioned that Stoker $^{6}$ and Ippen ${ }^{7}$ had indicated how finitedifference numerical techniques could be applied to such problems but had not presented any solutions. The Authors are therefore unaware that considerable advances have already been made in the United States in the development of procedures similar to theirs for analysing the oscillations of harbour basins. The main purpose of the present discussion, then, is to indicate the directions in which this development has proceeded overseas.

47. Two almost parallel developments occurred in 1965 in two non-related studies by Raichlen ${ }^{12}$ and by Wilson, Hendrickson and Kilmer. ${ }^{13}$

48. Raichlen followed the 'talweg' procedure of Defant ${ }^{14}$ to divide a given closed basin of arbitrary shape and depth into $N$ equispaced vertical cross sections (normal to the talweg), whose areas $A$ and surface widths $b$ are derivable from charts and therefore considered known quantities. The governing equation that has to be satisfied along the $s$-direction of the talweg may be shown to be

$$
\frac{\partial}{\partial s}\left[A(s) \frac{\partial \eta}{\partial s}\right]+\frac{\sigma^{2} b(s)}{g} \eta=0 \quad . \quad . \quad . \quad . \quad .
$$

where $\eta(s)$ is the maximum amplitude of the seiche (independent of time). For each $n$th cross section of the total $N$ cross sections along the valley route, equation (35) is reducible to finite difference form:

$$
a_{n, n+1} \eta_{n+1}+a_{n, n} \eta_{n}+a_{n, n-1} \eta_{n-1}=\Lambda_{k} \eta_{n}
$$

in which the $a$ 's are all coefficients (functions of $A$ 's and $b$ 's) and $\Lambda_{k}$ is proportional to the $k$ th eigenvalue of the $N$ possible eigenvalues that satisfy the $N \times N$ matrix of equations. At $n=1$ and $n=N$, Raichlen assumed a zero surface slope condition, $\partial \eta / \partial s=0$, for the terminal antinodes of the oscillation.

49. Wilson et al. ${ }^{13}$ while following essentially the same procedure in their twodimensional approach to the problem of oscillations in open-mouth basins or bays, assumed a nodal condition at the mouth, $\left(\eta_{1}=0\right)$ and a condition at the head of the talweg that, for depth approaching zero $\left(h_{N} \rightarrow 0\right)$, yielded

$$
\left.\frac{d h}{d s} \frac{d \eta}{d s}\right|_{N}+\frac{\sigma^{2}}{g} \eta_{N}=0 \quad \text {. . . . . . . . }
$$

Equation (37) is an expansion of equation (35) for the particular condition $h_{N}=0$. In general the depth $h(s)$ is the mean cross-sectional depth $(=A(s) / b(s))$.

50. As a check on the matrix solutions in the above two-dimensional approach, Wilson et al. ${ }^{13}$ applied the method to four test cases, for which exact analytic solutions are known, namely:

(i) A triangular bay with uniformly sloping bed

$$
\left(L=67500 \mathrm{ft}, \quad b_{1}=150000 \mathrm{ft}, \quad h_{1}=560 \mathrm{ft}\right)
$$

(ii) A triangular bay with horizontal bed

$$
\left(L=67500 \mathrm{ft}, \quad b_{1}=150000 \mathrm{ft}, \quad h_{1}=560 \mathrm{ft}\right)
$$

(iii) A rectangular bay with uniformly sloping bed

$$
\left(L=45000 \mathrm{ft}, \quad b_{1}=125000 \mathrm{ft}, \quad h_{1}=560 \mathrm{ft}\right)
$$

Paper published: Proc. Instn civ. Engrs, 1969, 43 (June) 141-155. 
(iv) A rectangular bay with semi-parabolic bed

$$
\left(L=45000 \mathrm{ft}, \quad b_{1}=125000 \mathrm{ft}, \quad h_{1}=560 \mathrm{ft}\right)
$$

51. The results of the calculations are shown in Table 2. Within the limits of the 18-station division of the 'talweg' of each bay the results must be considered quite good.

52. Wilson, Hendrickson and Kilmer, ${ }^{13}$ however, also pursued the full threedimensional problem of oscillations in bays, using polar co-ordinates first of all,

Table 2. Exact and numerically derived modal periods for geometrical analogies to Monterey Bay

\begin{tabular}{|c|c|c|c|c|c|c|}
\hline \multirow{2}{*}{$\begin{array}{c}\text { Basin } \\
\text { type }\end{array}$} & \multirow{2}{*}{$\begin{array}{c}\text { Method } \\
\text { of } \\
\text { calculation }\end{array}$} & \multirow{2}{*}{$\begin{array}{c}\text { Fundamental } \\
\text { period, } \\
\text { min }\end{array}$} & \multicolumn{4}{|c|}{ Mode ratios, $T_{n} / T_{1}$} \\
\hline & & & $n=1$ & 2 & 3 & 4 \\
\hline (i) & $\begin{array}{l}\text { Analytic } \\
\text { Numerical }\end{array}$ & $\begin{array}{l}27 \cdot 7 \\
27 \cdot 4\end{array}$ & $\begin{array}{l}1.000 \\
1.000\end{array}$ & $\begin{array}{l}0.541 \\
0.546\end{array}$ & $\begin{array}{l}0 \cdot 374 \\
0 \cdot 376\end{array}$ & $\begin{array}{l}0.283 \\
0.286\end{array}$ \\
\hline (ii) & $\begin{array}{l}\text { Analytic } \\
\text { Numerical }\end{array}$ & $\begin{array}{l}21 \cdot 9 \\
23 \cdot 0\end{array}$ & $\begin{array}{l}1.000 \\
1.000\end{array}$ & $\begin{array}{l}0.435 \\
0.468\end{array}$ & $\begin{array}{l}0.278 \\
0.295\end{array}$ & $\begin{array}{l}0.203 \\
0.215\end{array}$ \\
\hline (iii) & $\begin{array}{l}\text { Analytic } \\
\text { Numerical }\end{array}$ & $\begin{array}{l}29 \cdot 2 \\
29 \cdot 0\end{array}$ & $\begin{array}{l}1.000 \\
1.000\end{array}$ & $\begin{array}{l}0.435 \\
0.424\end{array}$ & $\begin{array}{l}0 \cdot 278 \\
0 \cdot 272\end{array}$ & $\begin{array}{l}0.203 \\
0.205\end{array}$ \\
\hline (iv) & $\begin{array}{l}\text { Analytic } \\
\text { Numerical }\end{array}$ & $\begin{array}{l}24 \cdot 8 \\
24 \cdot 7\end{array}$ & $\begin{array}{l}1.000 \\
1.000 \\
\end{array}$ & $\begin{array}{l}0.409 \\
0.410\end{array}$ & $\begin{array}{l}0.259 \\
0.260\end{array}$ & $\begin{array}{l}0 \cdot 189 \\
0 \cdot 194\end{array}$ \\
\hline
\end{tabular}

(a)

(b)

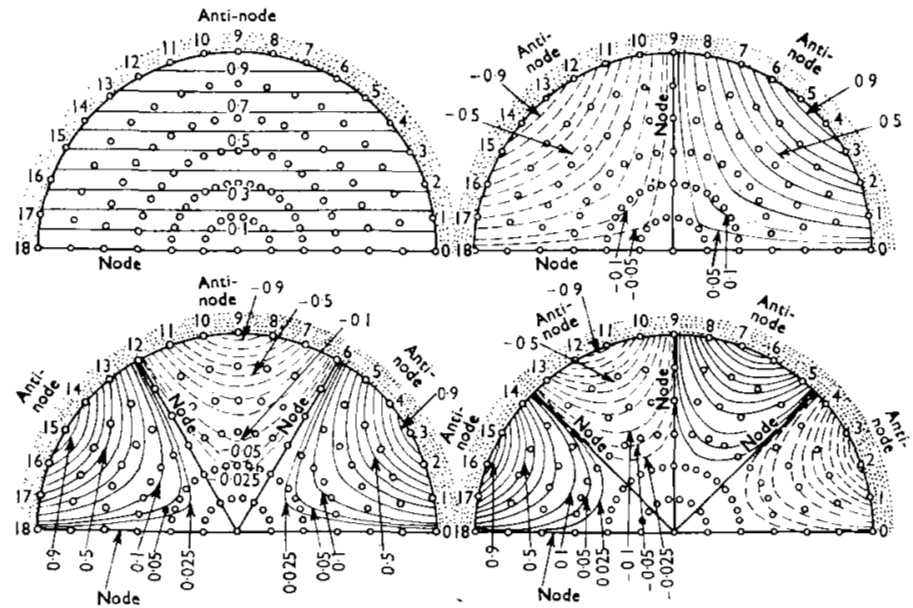

(c)

(d)

Fig. 9. Contours of water-surface elevation for four lowest modes of oscillation in a semi-circular basin with semi-paraboloidal bottom (numerical calculation) (from Wilson, Hendrickson and Kilmer ${ }^{13}$ ) 
because of their special adaptability to the crescent shape of Monterey Bay, California. Because of the unwieldiness of the finite-difference equations, it is not possible to reproduce here the details of this development. The reader must necessarily consult the reference. The method, however, proceeds from the same basic equation (5) used by the Authors, adapted to polar co-ordinates. The computer problem used in solving the eigenvalue problem was based on the Hessenberg Algorithm. ${ }^{15}$

53. As an example of the success of the numerical approach, Fig. 9 and Table 3 give the results of an $85 \times 85$ matrix test in exploring the lowest 10 modes of oscillation of a semi-circular bay with semi-paraboloidal bed, for which exact solutions are determinable from Lamb ${ }^{8}$ (Art. 193, pp, 291-293) (see also Wilson ${ }^{16}$ ). Fig. 9 gives the surface shape of the four lowest modes of oscillation, as found numerically; isolines define the contours of water level, normalized to unit value at the antinodes. Table 3 presents comparative ratios of modal periods (referred to the fundamental period) for the four lowest modes. It is characteristic of the numerical method that accuracy falls off as the modal number increases. This is evident in Table 3.

Table 3. Modes of free oscillation in openmouth semi-circular basin : exact and numerical solutions

\begin{tabular}{c|c|c}
\hline \multirow{2}{*}{$\begin{array}{c}\text { Mode number, } \\
n\end{array}$} & \multicolumn{2}{|c}{ Mode-period ratio, $T_{n} / T_{1}$} \\
\cline { 2 - 3 } & $\begin{array}{c}\text { Numerical } \\
\text { solution }\end{array}$ & $\begin{array}{c}\text { Analytic } \\
\text { solution }\end{array}$ \\
\hline 1 & 1.000 & 1.000 \\
2 & 0.708 & 0.707 \\
3 & 0.581 & 0.578 \\
4 & 0.509 & 0.500 \\
\hline
\end{tabular}

54. More recently (1968), Wilson, Jen, Hendrickson and Soot ${ }^{17}$ have applied the numerical three-dimensional matrix procedure with rectilinear co-ordinates in investigating some of the natural modes of oscillation of particular basins of the Los Angeles-Long Beach Harbour complex. Again, it is not possible in this discussion to dwell on the intricacies of this application. It will suffice to present an example of the output of the numerical calculation for a typical harbour basin-the coupled Southeast Basin and Basin Six of Long Beach Harbour.

55. Figure 10 shows the numerical modelling of the coupled basins. Crosses define boundary points and triangles intermediate points of the reticulation, for which water depths were specified. Numbers alongside station-points in Fig. 10 are stationidentification numbers. A total of 88 network points was used to cover the area and resulted in an $88 \times 88$ matrix of equations whose eigenvalue solutions yielded the 10 lowest modes of oscillation retained as being reliable among the 88 possible modes for the assumed condition of a node at the entrance of the basin.

56. Figure 11 gives the configuration of the water surface (at maximum amplitude) for the fourth mode, eigenperiod, $T_{4}=2.80$ minutes. Contours are isolines of water level, normalized to a maximum of 100 . Vector arrows indicate the direction of flow of the maximum current in the cycle: numbers printed alongside the vectors give the current strength in units/s, normalized to unit height of the maximum surface elevation. It is of interest that the fourth mode oscillation is not only binodal (with respect to the entrance), for the SE Basin alone, but is virtually binodal in an east-west direction for the coupled basin comprising Basin Six and the SE Basin.

57. As a check upon Fig. 11, the method of Leendertse ${ }^{18}$ was invoked in a 


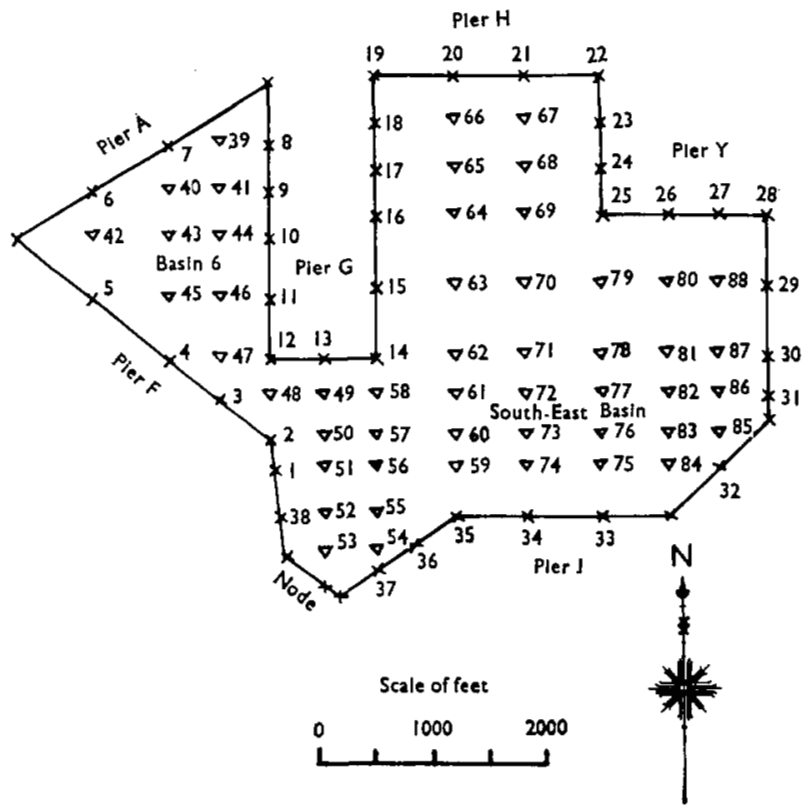

Fig. 10. Numerical model of existing SE Basin and Basin Six, Long Beach Harbour (from Wilson, Jen, Hendrickson and Soot ${ }^{17}$ )

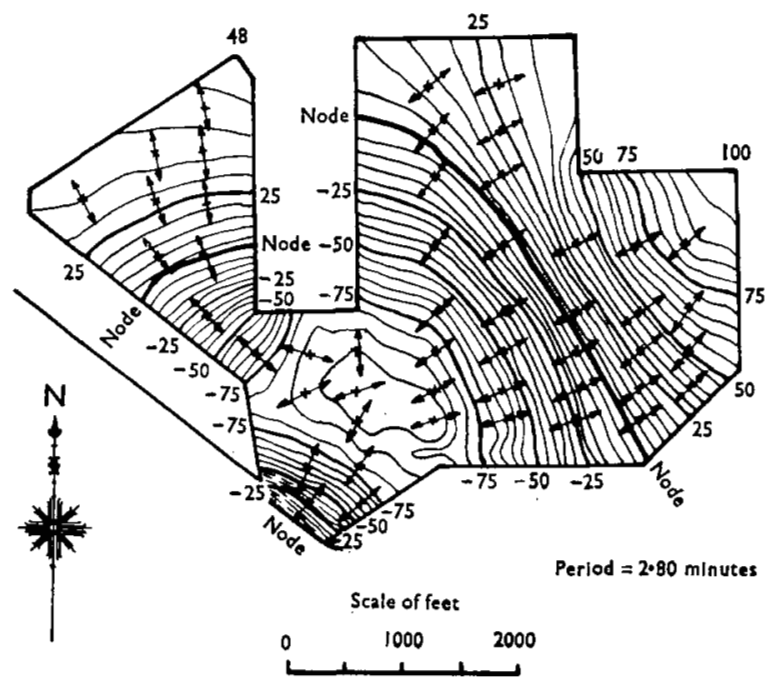

Contour lines in Increments of 5 , normalized to maximum surface elevation of 100 Velocitles in units per second, normalized to maximum double amplitude surface varlation of one unit. (Figures not Inserted alongside reactors to avold confusion)

Fig. 11. Fourth mode of free oscillation of the SE Basin and Basin Six, Long Beach Harbour, from numerical calculation (from Wilson, Jen, Hendrickson and Soot ${ }^{17}$ ) Downloaded by [] on [26/04/23]. Copyright $\odot$ ICE Publishing, all rights reserved. 


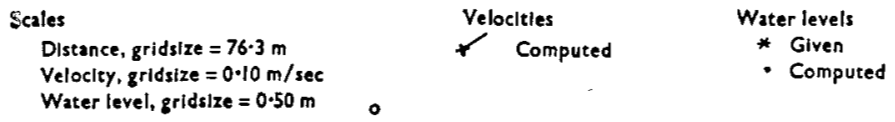

$\circ$

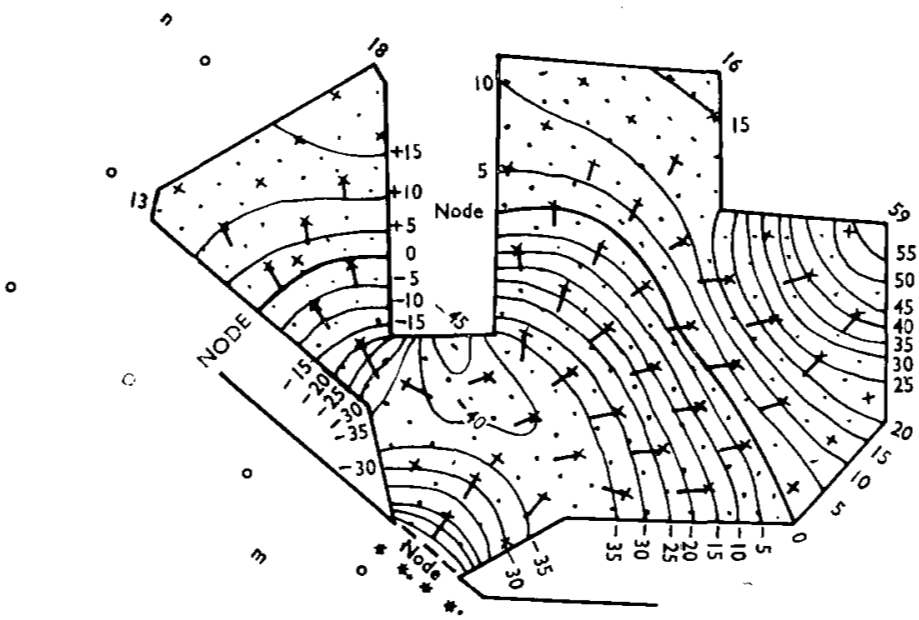

$\circ$

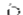

Fig. 12. Response of SE Basin and Basin Six, Long Beach Harbour, to $2 \cdot 8$ min (15 cm amplitude) long wave excitation impressed at the entrance, as calculated by the numerical method of Leendertse ${ }^{18}$ (from Wilson, Jen, Hendrickson and Soot ${ }^{17}$ )

numerical calculation to determine the nature of the steady-state oscillation developing in the coupled basins from a 2.80 min sinusoidal oscillation of $15 \mathrm{~cm}$ amplitude impressed on the entrance of the basin some distance towards the outside. Leendertse's programme includes consideration of both bed friction and Coriolis effect in the wave propagation and is based on two sets of difference equations of motion and continuity. The two sets are used in succession for a step by step solution in time. A stable solution is reached when the oscillation becomes completely repetitive. A significant advantage of the method is that it can handle a large number of reticulation points by which the geometry of the basin can be accurately specified: about 260 points were used to model the basin in question.

58. Figure 12 gives the maximum amplitude result of the application of Leendertse's numerical procedure (conducted at time-steps of $6 \mathrm{~s}$ and reached after 85 steps). The external oscillation of $2.80 \mathrm{~min}$ period not only establishes a node at the entrance in the exact position of the assumed node of Figs 10 and 11, but largely verifies the modal shape of the oscillation given in Fig. 11, both as regards nodal and 
antinodal positions and relative amplitudes. While Leendertse's time-step method is unable to predict, a priori, that an external wave of $2.80 \mathrm{~min}$ would be resonant for the harbour basin, it could accurately define the resonance if it were applied for a suitable number of trial periods near $2.80 \mathrm{~min}$. In general, it could be a valuable complementary procedure to refine the matrix-eigen-frequency determinations made by such methods as those of the Authors and of Wilson et al.

59. There remains to mention briefly the electric network method of Joy, ${ }^{19}$ which pursues work initiated by Ishiguro and others in the use of analogue computers, and the more recent development of Hwang and $\mathrm{Tuck}^{20}$ and of Hwang and Le Mehaute, ${ }^{21}$

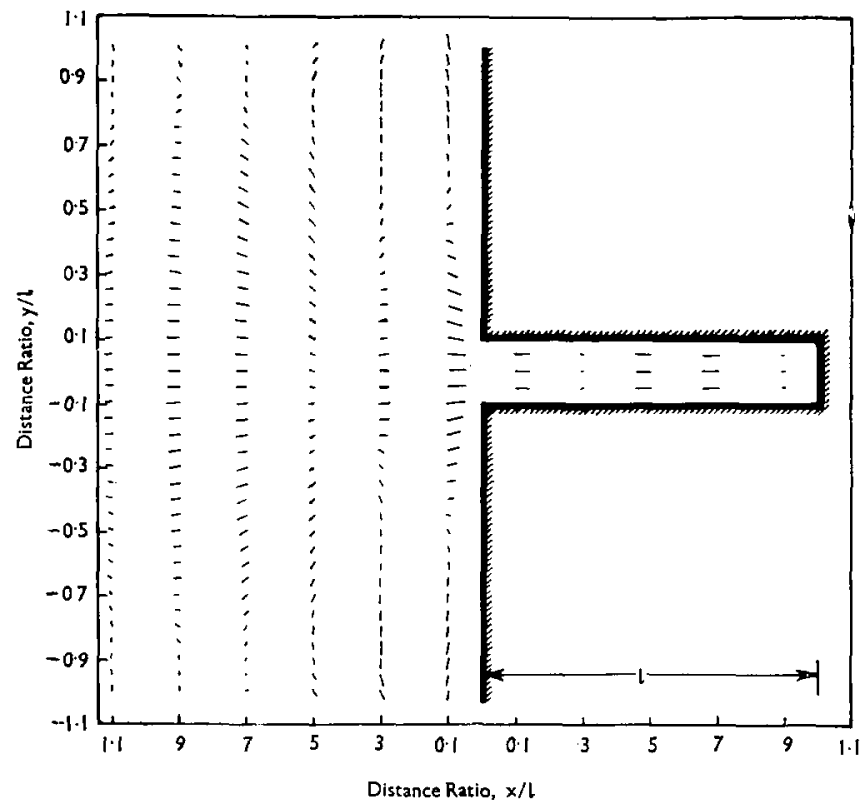

Fig. 13. Velocity field in and near a rectangular harbour of constant depth for an incident long wave train of dimension $\mathrm{k} 1=4$, normal to the coast (from Hwang and Le Mehaute ${ }^{21}$ )

which is of special interest. The latter Authors, working initially from the standpoint of an embayment of uniform depth, introduce a 'source function' $Q(X, Y)$ along the boundary $S$, which is dependent on the rectangular co-ordinates $X, Y$ on the boundary, and consider that the velocity potential $\phi(x, y)$ at any point $(x, y)$ in the domain of the bay (or outside in open water) is the sum of the contributions from the source distribution along the boundary and the influence of incoming waves from their origin in the open sea (at infinity). The effect of the boundary is expressed in terms of a Green's function $G(x, y ; X, Y)$ as

$$
\int_{\mathrm{s}} Q(X, Y) G(x, y ; X, Y) d s
$$

The final solution of the water motion at the point $(x, y)$ is, of course, far too complicated to reproduce here, and the reader again must be referred to the references. An advantage of the method is that it evades any arbitrary assumption as regards a nodal condition at the entrance of any given bay or harbour and considers the influence of 
the coastline adjacent to the entrance. At present the effects of friction have not been included in the calculation and adaptations to the usual situation of variable depth are still in hand. Fig. 13 gives an example of the velocity field calculated for a rectangular harbour abutting on a straight vertical-walled coastline in a situation of uniform depth.

\section{Mr S. M. Fisher, Napier Harbour Board, NZ}

While I appreciate that the Authors have presented a cheaper method of predicting the significant horizontal movements in a harbour, I consider that its relevance to the disturbance of berthed ships and thence to harbour design is limited by its failure to report water slopes which, in the harbours treated, are the cause of the greatest force initiating ship motion. ${ }^{23}$ I suggest that, to predict the disturbance of ships in berths, a model is still required. A reliable but expensive model would be big enough for the mooring forces of ships to be measured. A smaller, cheaper and probably satisfactory model would use a starry sky, with three stars over each berth. For further economy, the number of tests can be minimized by modulating the period of the waves attacking the harbour, as was done at the Hydraulic Research Station, Wallingford, ${ }^{23}$ during tests to guide the design of a lee breakwater and narrow entrance at Napier.

61. Another cheap method, requiring only a small model, measures the differences between the levels at the quarter points of each berth and, in the case of a pier, at each side of the pier also. The first such prototype slope gauge has just been installed at Napier to show, by comparison with a simultaneous record of the ocean waves, the effect of breakwater construction.

\section{Dr Taylor, Mr Patil and Dr Zienkiewicz}

The above discussion provides an excellent summary of the 'standard' methods for solving the phenomenon of harbour oscillation. However, this in no way alters the state of knowledge or numerical techniques available at the time we submitted our Paper.

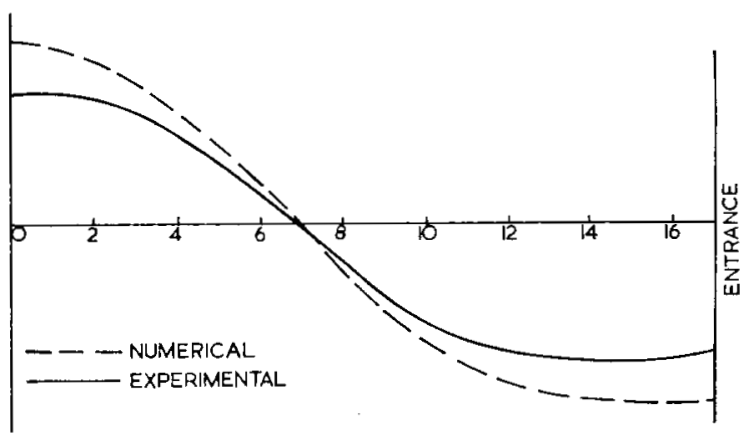

Fig. 14. Comparison of mode shapes : rectangular harbour

63. The prime intention of the Paper was to outline a different method of approach, using the same basic equations, to arrive at the solution in an efficient manner. Indeed, this can easily be extended in order to obtain the response of a harbour to any long wave action at the entrance by one of two methods-superposition of modes ${ }^{24}$ or a step-by-step timewise iteration technique. ${ }^{25}$

64. Although the first method is usually limited to undamped systems an adequate indication of the numerical techniques including damping has been presented. ${ }^{26}$ As an example of the application of the method, the Authors considered a rectangular 
harbour of varying depth, from 2 in. at the entrance to 4 in. at the rear, and 12 in. $x$ 17 in. in plan, and a typical response to a long wave of $0.85 \mathrm{~s}$ period at the entrance. As expected, the superposition technique gave an overestimate as shown in Fig. 14. By a suitable transformation this method can be used for periodic or non-periodic waves.

65. The stepwise technique, which can be adapted to include both linear and nonlinear damping, results in a recurrence relationship which can be written in the form

$$
\frac{1}{\delta t^{2}}\left[\left[K^{1}\right]+\delta t^{2}\left[K^{2}\right]\right]\{\ddot{n}\}_{\delta t}=\frac{1}{\delta t^{2}}\left[\left[K^{3}\right]\{\ddot{n}\}_{o}-\left[K^{4}\right]\left\{n_{0}\right\}-\delta t\left[K^{5}\right]\{\ddot{n}\}_{o}\right] \text {. }
$$

where $\left[K^{1}\right] \ldots\left[K^{5}\right]$ are square symmetric matrices, suffices ' $o$ ' and ' $\delta t$ ' refer to initial conditions and conditions after a time ' $\delta t$ ', respectively. Details of the derivation of the recurrence relationship and examples may be obtained from references 25 and 27 .

66. Since the discretization allows for the immediate inclusion of flow through the entrance, loc. cit. when using the stepwise method, a better estimate of the response under prototype conditions should be obtained.

67. In reply to the query raised by Mr Fisher in his first paragraph, the Authors would like to point out that the water slopes at each point, in $x$ and $y$ directions have been calculated and averaged over the element. Under the articles 30 and 31 the basic ideas underlying the method have been clarified.

68. In reply to his second paragraph, we would like to add that a modified 'starry sky' type of technique was used to measure the actual significant horizontal movement of water in the rectangular and circular harbour models mentioned in the Paper.

69. The Authors do not overrule the importance of a model study, in understanding fully the effect of damping and the response characteristics of a harbour, in predicting the actual water slope distribution or the significant horizontal movement over the harbour region under consideration.

\section{References}

12. RaICHLEN F. Long period oscillations in basins of arbitrary shapes. Proc. Am. Soc. civ. Engrs Confce on coastal engineering, 1966, 115-145.

13. Wilson B. W. et al. Feasibility study for a surge-action model of Monterey Harbour, California. Contract Report No. 2-136. Waterways Experiment Station, US Army Corps of Engineers, Vicksburg, Mississippi, 1965 (Oct.) 166.

14. Defant A. Physical oceanography. Pergamon Press, 1960, 2, Chaps VI, XVI.

15. Crandall S. H. Engineering analysis. McGraw-Hill, New York, 1956, 86-91.

16. WILson B. W. Seiche. Encyclopedia of oceanography. Rheinhold, New York, 1966, 804-817.

17. Wilson B. W. et al. Wave and surge action study for Los Angeles-Long Beach harbors. Tech. Report to US Army Corps of Engineers Los Angeles District, Los Angeles, California, 1968 (July) 362.

18. LEENDERTSE J. J. Aspects of a computational model for long-period water-wave propagation. Memorandum RM-5294-PR, RAND Corp., Santa Monica, California, 1967 (May) 165.

19. Joy J. W. Practical use of electric networks to simulate or predict seiche conditions in harbors. Confe on coastal engineering, Santa Barbara, California, 1965, Proc. Am. Soc. civ. Engrs, 1965 (Oct.) 87-110.

20. Hwang L-S. and Tuck E. O. On the oscillations of harbors of arbitrary shape. J. Fluid Mech., 1969 (publication pending).

21. Hwang L-S. and Le Mehaute B. On the oscillation of harbors of arbitrary shape from periodic and non periodic wave trains. Paper presented at $A \mathrm{~m}$. Soc. civ. Engrs Confce in Hydraulic Engineering, Logan, Utah, Aug., 1969. 
22. Joglekar D. V. and Kulkarui P. K. Mooring problems in harbours subject to seiches and tidal bores, XIX International Navigational Congress, 1957, London.

23. Napier Harbour Board, New Zealand Report no. Ex. 416. Hydraulics Research Station, 1968 (Sept.).

24. Patil B. S. Harbour resonance. PhD thesis, University College of Swansea, 1970 (Feb.).

25. Davis J. M. A finite element solution of the second order time dependent wave equation. MSc thesis, University College of Swansea, 1969.

26. Zienkiewicz O. C. and Cheung Y. K. The finite element method in structural and continuum mechanics. McGraw-Hill, 1967.

27. Kibirige S. et al. A finite element solution of the wave equation using a reduced variational formulation. Instn civ. Engrs Confee on Dynamic Waves, 7-9 July, 1970, Session 7, Paper 3. John Wiley, London. 